\title{
LANGUAGE AS A FORM OF HUMAN BEHAVIOR ${ }^{1}$
}

\author{
EDWARD SAPIR
}

So long as the facts of speech are discussed only by students professionally interested in language its peculiar characteristics are very likely to be overlooked. It is not surprising, therefore, that philologists and teachers of particular languages are apt to have vaguer and cruder notions of the fundamental characteristics of human speech than such unspecialized students of human behavior as concern themselves with this most human of all reactive systems. It is clear that if we are ever to relate the fundamental problems of linguistic science to those of human behavior in general - in other words, to psychology — we must learn to see language as possessed of certain essential characteristics apart from those of particular languages that we may happen to be familiar with and as rooted in some general soil of behavior that gives birth to other than strictly linguistic forms of expression.

If we take a bird's-eye view of the languages of the world we find that there are certain things that characterize them as a whole and that tend to mark them off somewhat from other forms of cultural behavior. In the first place we are struck by the marvelous completeness of formal development of each and every language that we have knowledge of. Popular opinion to the contrary, there is no known language, whether spoken by a culturally advanced

${ }^{1}$ An address delivered before the joint session of the National Council of Teachers of English and the English Language Congress at Philadelphia, November, 1926. 
group or by one of the more backward peoples of the world, which has not its perfectly definite phonetic system, its clearly developed and often very complex system of forms, and its established rules and idioms of usage. In other words, there is no such thing as a language that has not its well-defined grammar, though it goes without saying that this grammatical system is never consciously known or capable of communication by the untutored folk. We may further say of all normal forms of human speech that they have the appearance of systems of behavior that are rather definitely marked off from all other organizations within the general range of conduct. When we deal with such flexible categories of socialized behavior as religion or art or government or education, it is difficult to draw convincing lines. A given reaction may be placed now here, now there, but there seems never to be any reasonable doubt as to the formal identity of a speech act. This is all the more remarkable as speech is not in actual life handled as a self-satisfying reactive system. It comes into use and consciousness merely as a general lever for all types of expression. There is no pure linguistic conduct. There is only conduct in which the need is felt for communication or expression and in which this need is solved with the help of an elaborate linguistic apparatus, always ready to hand.

We are learning to attribute more and more importance to the part played by the unconscious mind in the development of our habits. We realize more clearly than the psychologists and philosophers of the past have realized that the consciously controlled type of behavior is always a secondary type, and that all intellectual formulations are little more than a conscious control, in set terms, of knowledge that is already possessed in an unconscious or intuitive form. It is characteristic of the more important types of socialized conduct that they tend to draw the attention of individuals and societies to themselves and thus become an object of conscious formulation-in other words, of scientific study. It does not follow, however, that a scientific statement of facts, say of religion or other aspects of social conduct, is more accurate or more delicately nuanced than the intuitive knowledge and control which preceded it. One may have, and often does have, an astonishing fineness of intuitive control without being in the least possessed of an even 
elementary knowledge of the reactive system as such. Hence it is not surprising that statements made by sophisticated, no less than by more naive, people about their own forms of speech and about the nature of their linguistic responses are often wide of the mark. It is well known that Plato indulged in extraordinarily childish speculations on the nature of the Greek language.

We must, therefore, carefully refrain from making the common mistake of confusing the intuitively felt complexities of language with an intellectually controlled statement of them. If we do not learn to make this important distinction we shut ourselves off from the possibility of understanding the marvelous formal intricacy of so many of the languages of primitive man, and-what is of more general interest - of understanding how the child is able to acquire as firm and accurate and extended a control of linguistic habits as he does. Long before the child knows the difference between a singular and a plural, long before he has any notion that there is such a thing as tense, he has learned to use the categories of number and tense with perfect freedom and comfort. With the development of civilization, language has tended more and more to rise into consciousness as a subject of speculation and study; but it still remains characteristic of language as a whole that of all the great systems of social patterning it is probably the one which is most definitely unconscious in its operation. But the unconsciousness of the speech processes is not to be interpreted in any vague or mystic sense. All that we mean is that our intuitive sense of the relations between forms of expression is keen enough to enable us to acquire a full control of speech habits without the necessity of an intellectual overhauling. The clarity and certainty of this intuitive process is best evidenced by the fact that when natives who have never learned the grammar of their own language come in contact with a field investigator who endeavors to discover this grammar by inductive methods of inquiry, the natives often develop-and in a short time-a very real comprehension of what the inquirer is after. They can often help him with the statement of explicit rules and with observations that could never have occurred to them in the normal course of their daily life.

The next and most obvious of the general features of speech is 
its indirect or symbolic character. No normal speech utterance really means what it biologically seems to mean. In other words, if I move the lips or tongue or glottal cords in this or that fashion it is not because these movements are of any direct use in my adjustment to the environment. It is because by means of these movements I am able to effect articulations that are perceived as arbitrary sequences of sounds conveying more or less definite notions which stand in no intelligible relation to the articulations themselves. If I move my tongue in order to lick a piece of candy I carry out a movement which has direct significance for the desired end, but if I put my tongue in the position needed to articulate the sound " 1 " or a given vowel, the act is in no way useful except in so far as society has tacitly decided that these movements are capable of symbolic interpretation. It is highly important to realize that symbolic systems, which are systems of indirect function, are not in theory confined to speech. One may have a pantomimic symbolic system or any other kind of symbolic system developed by some part of the organism, but it remains strikingly true that no other human type of symbolic behavior compares for a moment in completeness or antiquity or universality with the symbolism known as speech. It is further important to observe that there seem to be no appreciable differences in the languages of the world in regard to their relatively symbolic character. The sound sequences that are used as symbols of reference by the Hottentot or the Eskimo are to all intents and purposes as arbitrary as those used by a modern Englishman or Frenchman or German.

This brings us to what is, in some respects, the most surprising fact about language: that, universal as it is, it is at the same time the most variable of all human institutions in the actual detail of its overt expression. All types of religious belief, all systems of decorative art, all kinship systems, all methods of organizing society have certain unmistakable things in common so far as their actual content is concerned; but when it comes to speech, which is more deeply rooted in human society than any one of these systems of activity, we find that its actual content in terms of words, linguistic forms, and methods of articulation is almost infinitely variable. We must conclude from this that what is fundamentally character- 
istic of speech at any given time and place is not its overt form, which can only be understood as the resultant of a very complicated series of historical circumstances, but its ground plan. Languages do not profoundly matter. It is the habit of language as such that is of such tremendous importance for humanity. The best proof of this is the ease with which human beings learn to pass from one language to another and the ease with which they transfer from one symbolic medium to another-from oral speech to writing, from writing to the telegraph code, and so on indefinitely. It comes to this: that language cannot be adequately defined as a set of physical habits, but must be understood rather as an arrangement, for purposes of communication and expression, of all the elements of experience in accordance with a complex system of intuitively felt relations that can choose any perceptible tokens or symbols they have a mind to.

So far we have been assuming that the task of language is a purely denotive one; that when we say "horse," for instance, our sole purpose is to convey a reference to a class of well-known animals. If we look more closely at what actually happens in human speech, however, we are impressed by the fact that the denotive function of speech is always compounded with certain expressive factors which we are in the habit of leaving out of account in our formal designations of linguistic processes, but which are always present in the actual life of language. It is impossible to pronounce even so indifferent a word as "horse" without a lesser or greater show of interest, without some change of emotion. This expressiveness may relate to our personal attitude toward horses in general or to a particular horse that has been called up as an image in our minds. Or very frequently, too, the expressiveness of articulation may have nothing to do with the animal but may relate to our attitude toward the person that we are speaking to or thinking of, or to our own general state of mind. In extreme cases our pronunciation of the word "horse" may be infinitely more significant as revealing a distracted state of mind or an intense interest in the person spoken to than as a pure denotive symbol. It becomes clear that in the course of our speech activities we are really doing two rather distinct things, though these are never to be completely sun- 
dered except by a process of abstraction. On the one hand, we are using words as algebraic symbols for classes of ideas to which we refer certain individual references that we wish to make. On the other hand, we are giving some hint of our attitude toward these ideas or toward some of the things or persons present in the background of the speech act. It is because we are alert to the endless conflict between the denotive and the expressive aspects of speech that we can safely interpret many words or phrases or statements in a sense that is completely at variance with their supposed meaning. If a man slaps his friend on the back with the remark that he is a "rascally dog," he knows very well that his words will not be understood to mean what they seem to mean. Again, measured words of praise may be so uttered as to amount to an insult. All these remarks are commonplaces, but their importance is perhaps not sufficiently understood by students of language. We have been too successfully schooled by the grammarians and the systematizes of speech phenomena to have much charity for these apparently dubious or secondary uses of speech. But what if it turned out, in the upshot, that these usages are not as secondary as they seem, that we have reason to believe that in the remote past, when language was beginning to emerge as a symbolic system, its use was even more expressive than at present? What if language were merely conventionalized gesture-using the word "gesture" in its widest possible sense as indicating any form of expression?

A parallel from an entirely unconnected type of human behavior may be useful at this point. If I am very much angered by something that one has said or done, I may so forget myself as to lunge forward with the obvious intention of hitting him. My reaction would be directly expressive in a functional sense. Now, I may inhibit the reaction without entirely destroying its form. There may be enough of the gesture left to make it obvious to the bystanders that I had had the impulse to strike. This abbreviated or rudimentary gesture will then be felt as in some sort a symbol of my attitude. But it is an individual symbol which I have created, at it were, on the spur of the moment, and which is not to be interpreted in accordance with an artificial social code. But suppose, further, that this gesture becomes accepted by society at large as a 
pantomimic symbol of the striking act, then we have what amounts to all intents and purposes to an unemotional, denotive symbol of the notion of striking. It would then be possible for human beings to use such a gesture for purposes of reference only. They would not necessarily feel the impulse to strike when they used the pantomimic gesture for it. Now it is, of course, perfectly obvious that rudimentary symbolisms of this sort are constantly being created by individuals and that they tend to become more or less characteristic of our varying social groups, but they have never succeeded in elevating themselves to the status of universal symbolisms of reference. What if speech were, at last analysis, a highly conventionalized system of just such expressive gestures which by constant use had lost their original expressive content, having been rubbed down to the status of purely referential symbols?

In order clearly to understand the point of view that we are trying to develop it is necessary to take a glance at human responsiveness in general. We shall then be able to put speech in its proper perspective, to see it, not as the extraordinarily isolated and peculiar thing that it at first seems to be, but as a highly evolved product of a type of activity that is far more general in scope. In the case of the arrested gesture of striking that we discussed before there was an obvious resemblance between the activity that resulted from the impulse to strike and the eventually pantomimic symbol built up out of it. But a more inclusive observation soon discloses the fact that symbols need not arise in quite so simple a manner.

We are in the habit of looking at all forms of human activity from a functional point of view. A man moves his jaws when engaged in the act of eating in order to prepare the food for swallowing. He moves his limbs in order to walk. He strains his eyes in order to see more clearly. He lifts his voice in order to reach the ears of a distant person. And so on indefinitely. But these obviously functional acts by no means constitute the sum total of human behavior; it becomes necessary to inquire if a large portion of this behavior may not be interpreted in other than strictly functional terms. We may return, for purposes of illustration, to the example that we gave before. It is perfectly true that the act of 
lunging forward and of beginning to use the hands is the central fact in the response of the angry individual, and is, for that reason, likely to be the only one that engages our attention. But it is true to say that the whole body participates in the response in some form or other. The eyes, the brows, the toes, and any number of other organs or systems of organs are involved in the angry response and can in a sense be said to help along the central response by a kind of sympathetic imitation. In other words, we have reason to believe that the particular part of the body that carries out a given act is always accompanied by other segments of the organism, which lend their consent, as it were, in symbolic form. It is essentially artificial, for instance, to think of the expression of wonder as bound up with the staring eyes alone. There will be something about the tension of the hands and about the whole set of the organism that is in some manner corroborative of what the eyes disclose. If, for one reason or another, the central expressive organ or system of organs is inhibited, the energy of the impulse may concentrate in some other part of the organism, so that the secondary expressive symbol may become the symbol par excellence. The more highly evolved we become as socialized individuals whose business it is to inhibit many of our expressive impulses, the more likely it is that these impulses find lodgment in parts of the organism that were not primarily designed, so to speak, for such expressions. The facts that I allude to are familiar enough, though they are probably rarely seen in their true generality. If I cannot box a man on the ear, I can at least double my fist behind my back or quietly stick out my tongue at him when he is not looking. These are merely overemphasized symbols of a type which are present in embryo in the natural consummation of the striking gesture. The tongue darts forward as a functionally ineffective but symbolically relieving substitute for the striking act itself.

Let us now return to speech. There is no reason to believe that speech articulations are different from any other expressions of the human body. At moments of intense excitement, when the current patterns of society fall away from us, the articulatory apparatus is very likely to regress into its primitive condition, and we produce all kinds of involuntary sounds that are highly expressive of our 
emotions or impulses. In ordinary life these emotions and impulses merely color speech, which has come to be an essentially denotive system. But we may surmise that in the remote past speech was neither more nor less than a series of auditory gestures, directly symbolizing various types of adjustment to the environment. These auditory gestures would have arisen, then, as substitutive symbols for activities or other expressions which it was not possible or convenient to effect at the time. Thus, one's natural impulse in describing a large object is to move the arms in a more or less circular fashion suggesting the notion of bigness. According to the theory that we are now developing, other parts of the organism would be expressing the notion of bigness in other and more indirect ways. The speech apparatus would help along in the expressive symbolism by parting the lips, dropping the tongue as low as possible, rounding the lips, sinking the pitch of the voice, and in other ways. If anyone is inclined to doubt the reality of such involuntary symbolisms in speech, let him try the following experiment, which I have myself tried a number of times with practically 100 per cent success. Let him tell a number of people, or a class, that there are three imaginary words: "la" (rhyming with "pa"), "law," and "lee," all meaning "table," but with a connotation of difference of size. Let them then tell which of these three hypothetical words indicates the big table, which the little table, and which the middle-sized table. I think it will be found that the normal English-speaking person, or French-speaking person, for that matter, will think of "lee" as symbolizing the small table, "law" the big table, and "la" the middle-sized table or table par excellence. This simply means that even at this late day we have not lost the feeling for the gesture significance of sounds and combinations of sounds. If we examine these three imaginary words more closely from the phonetic point of view, we find that the responses are well justified. The pronunciation of the vowel "ee" of "lee" is such as to demand a shortening of the distance between the tongue and the roof of the mouth, as contrasted with the pronunciation of the "a" of "la," in which the tongue articulates lower and farther back. Similarly, in "law" the tongue drops still more, the lower jaw also drops a little, and there is a slight tendency toward lip rounding. These phonetic 
modifications amount to gestures, the "ee" gesture being in effect an expressive symbol for smallness, the "aw" gesture a similarly expressive symbol for bigness.

All that is claimed here is that if we see sound articulations as highly variable and intuitively intelligible symbolic gestures, we have all we need to explain the phenomenon we call speech. The precise how and when and where of the historical development of speech is of course another matter. We must assume that speech expressiveness was highly variable, in an individual sense, to begin with; that only very slowly and painfully did groups of individuals come to look upon certain of these symbols as possessing a fixed symbolic significance; that once an expressive symbolism had been fixed by social habit, it could lose its expressive content and take on a denotive one, as in the case of the pantomimic gesture we discussed before; and that, finally, owing to the changes, unconscious and ceaseless, which set in to blur the original outlines of any social pattern of conduct, the actual sounds used for any symbol of reference would in course of time depart so widely from their original form as to obscure the whole mechanism of gesture symbolism which gave rise to the speech process in the first place. It should be carefully noted that this theory of the nature and development of speech is only superficially similar to the older interjectional and onomatopoetic theories of speech which used to be current in linguistic circles. If our view of the nature of speech is correct, it follows that the denotive function of speech, which we now conceive to be its primary function, is in actual fact a secondary one, just as it is a secondary fact that one shakes one's fist at an enemy, not in order to initiate the act of striking, but to indicate in a picturesquely symbolic manner that one has no use for him and might punch him soundly under appropriate circumstances. It may be suggested at this point that students of speech psychology could hardly do better than work out experiments intended to test to what extent imaginary speech forms can be constructed that are capable of intuitive interpretation in a primary symbolic sense. We see that language, in short, has embodied two distinct strata of symbolic expression, a primary gesture symbolism and a secondary referential one which has largely swamped the former. We 
can, therefore, see why it is that all normal speech involves a conflict between, or intertwining of, two distinct strata of expression or types of mechanism, one of which has to do with direct expression, the other with indirect or denotive expression.

It is legitimate to ask why language, a system of articulated and perceived sounds, is the one kind of symbolic system that all human beings have developed in the course of cultural evolution. I believe that the answer is not difficult to find. Most of the available parts of the human organism are in constant demand for directly functional purposes. This was even more true in the earliest stages of human development than today. The muscles of the hands and feet were too busily engaged in grasping, striking, walking, running, climbing, and other directly useful activities to make it possible for a successful symbolism to develop with their aid alone. The case was different with the so-called "organs of speech." The primary purpose of these organs, which include the larynx (more particularly the glottal cords), the nose, the palate, the tongue, the teeth, and the lips, is respiration, smelling, and the handling of food, of which the first and the last are by far the most important. Respiration is so nearly automatic a type of behavior that any symbolisms that might be secondarily worked out with the help of the larynx, the nose, and the mouth would interfere with it to only a slight extent. The chewing and swallowing of food is far less automatic, but occurs so seldom in actual practice that the organs needed for these important acts are most of the time left free for secondary activities. In other words, they are in a strategic position for the development of just such secondary symbolisms as we have shown were within the reach of all other parts of the organism as well. If this is true, speech is what it is, not because there is a mystic connection between articulated sounds and thought, or the process of symbolization, but merely because the general tendency of the human body to develop symbolic modes of expression over and above the directly functional ones found favorable soil in the tract known as the "organs of speech." An individual who does not need to earn his living by the constant use of his fingers for primary purposes may develop great virtuosity as a pianist. In precisely the same way the organs of speech developed 
special social virtuosity as symbol executants because they were idle enough of the time to make such a luxury possible.

The two aspects of speech, expressive and referential, are rarely seen in their purity. In the workaday world they are constantly intertwining their functions in countless compromises, and it is this highly variable process of compromise that is so largely responsible for the misunderstandings and clashes of human contact. If words really meant what we say they mean, there should be little room for misunderstandings; but it is of course only too true that they rarely mean quite what in our moments of intellectual isolation we claim as their due significance, but that they convey thousands of connotations over and above this ostensible meaning of theirs. Now, it is clear that with the growth of the power of analysis there is an ever increasing demand for the development of a perfectly objective and unemotional set of symbols that can stay put and mean exactly what they are supposed to mean-no more, no less. The more exact a system of thought becomes, the more impatient it is apt to be with the rough-and-ready symbolisms of normal speech. Hence it is not surprising that the mathematical disciplines have been driven to invent a great many special symbols which can be defined with complete accuracy and which will allow no room for expressive modifications. A plus sign that left any room for doubt as to its meaning would be useless. But language as ordinarily handled by society is soaked with overtones or connotations that are nicely felt by the members of the particular society that makes use of one of its specific forms, but that it is difficult to convey to outsiders. One may know the vocabulary and the grammar of a foreign language ever so well, but one is not likely to use it with that unconscious appeal to the expressive values that attach to those words and forms unless one has spent a considerable time among the people who use it or unless one as a child is very much more impressionable to these values than we adults normally are.

Language would be a poorer thing than it is if it were a denotive system alone. But we must not be so sentimental as to overlook the equally obvious fact that it is precisely the expressiveness of particular languages that makes any one of them a misleading or even a dangerous tool for the problem of sheer reference. The 
necessity of evolving a complicated denotive symbolism that is absolutely, or so far as may be, devoid of expressive values is not very keenly felt by normal human beings, but it is more than likely that as time goes on this purely speculative need will become more and more imperative. International complications, for instance, must be avoided at all costs, and there is perhaps no one device which would do more to eliminate the subtle misunderstandings which arise from the use of language as we ordinarily handle it than a system of symbols which are as cold-blooded as those used by the mathematicians, but which are inclusive enough to provide for every possible kind of communication. We must, then, conceive the essential task of an international language to be not so much the choosing of this or that particular form of speech, but the creation of a system of symbols of maximal simplicity and of absolute lack of ambiguity. The task of constructing such a system is far more difficult than it seems to be at first blush. Esperanto and other systems that have been suggested are to an amazing extent little more than translations into new terms of old habits of reference, the expressive "plus" being always included. One of the great tasks of the future may be the creation of such an objective language of reference from which every possible nuance of individual or social expressiveness has been removed. Perhaps such a system is philosophically inconceivable; but the history of mathematical and other scientific symbolisms shows clearly that the tendency has been toward the creation of just such a system. It goes without saying, however, that a purely denotive language need not and is not in the least likely to supersede the actual languages in use today, with their bewildering flexibility of individual and social expressiveness. These are likely to remain for incalculable periods to come. 